\title{
A study to know the knowledge, attitude, and practices of patients of bronchial asthma
}

Introduction: Asthma being a chronic inflammatory disease needs treatment for prolonged duration. To increase treatment compliance, each patient should know the course of disease, its precipitating factors, and management protocol. Despite the magnitude of the asthma, very little is known about its public perception. Aim: This study was done to know the knowledge, attitude, and practices of patients of bronchial asthma. Materials and Methods: In this prospective study, subjects were asthmatic patients attending the department of pulmonary medicine, KGMU Lucknow, India. A questionnaire including general understanding of asthma, its triggers and management was given to each patient and results were recorded. Results: A total of 140 patients with confirmed diagnosis of asthma were included in this study. On an average, each patient had already visited 3.2 doctors prior to coming to us. Out of 140 patients, $64 \%$ patients were ignorant regarding disease etiology, $47.1 \%$ patients thought that their disease is fatal, $30 \%$ patients were reluctant to accept the diagnosis of asthma. Regarding precipitating factors, $25.71 \%$ patients could not relate to any cause with their disease exacerbation. A total of $62.14 \%$ patients used alternative system of medicine too in the hope of getting rid of their disease. Oral medications were preferred by $62.1 \%$ patients, while $73.6 \%$ were using inhalers and out of them $71.8 \%$ were using inhalers incorrectly. Conclusion: Patient education program should augment awareness; eliminate social stigma, and misconcepts in the community regarding asthma. Knowledge about the prevailing perception in community would be the first step in achieving this.

S K Verma², Rajiv Garg ${ }^{2}$, Santosh Kumar', Ajay Kumar Verma², Ved Prakash ${ }^{2}$

Departments of Pulmonary Medicine, Government Medical College and Hospital, Chandigarh, ${ }^{2}$ King George's Medical University, Lucknow, Uttar Pradesh, ${ }^{1}$ Vallabhbhai Patel Chest Institute, New Delhi, India

Address for the Correspondence:

Prof. Rajendra Prasad, Vallabhbhai Patel Chest Institute, University of Delhi, Delhi - 110 007, India.

E-mail: rprasadkgmc@gmail.com

\begin{tabular}{|l|}
\hline Access this article online \\
\hline Website: www.ijmedph.org \\
\hline DOI: 10.4103/2230-8598.118959 \\
\hline Quick response code: \\
\hline
\end{tabular}

\section{INTRODUCTION}

Asthma is a chronic inflammatory disorder of airways in which many cells and cellular elements play a role. The chronic inflammation is associated with airway hyperresponsiveness that leads to recurrent episodes of wheezing, breathlessness, chest tightness, and coughing particularly at night or in early morning. These episodes are usually associated with widespread, but variable, airflow obstruction within the lung that is often reversible either spontaneously or with treatment. Exact cause of asthma is not known. It could be partly genetic and partly environmental in origin. ${ }^{[1]}$ The World Health Organization recognizes asthma as a major health problem. ${ }^{[2]}$ Asthma can occur at any age but children and young adults are the commonly affected age groups. Both sexes are affected almost equally though slight differences in prevalence between males and females have been reported. Although asthma cannot be "cured," clinical episodes can largely be prevented and controlled by proper management.

Both the physician as well as patients play a pivotal role for the under treatment and mismanagement of the disease. This causes concern in the field of asthma care. Despite the magnitude of the problem, very little is known about the public perception to the diagnosis and the impact of asthma on individuals, their families, and communities. ${ }^{[3,4]}$ Health education about asthma should include simple information about the types of treatment available, the rationale for the inhaled drugs, different inhaler devices, and techniques. Patients should be advised about preventive measures including avoidance of allergen exposure and air pollution. During the patient education sessions, the concept of peak expiratory flow (PEF) monitoring should be considered as appropriate to the patient's age, education, and socioeconomic status. Patients with moderate to severe disease should receive training to measure and record PEF. ${ }^{[1]}$ Patient should record and interpret their PEF. This helps to monitor 
the effectiveness of therapy and gives early warning of deterioration of asthma, so self-management plan can be promptly implemented. A recent systematic review by the Cochrane Airways group compared self-management plan with usual care and showed significant benefits in the intervention groups in terms of reduced morbidity and reduced use of health services. The effects were greatest where the intervention involved the issuing of written self-management action plans. ${ }^{[5]}$ Lifestyle modification should include regular balanced diet and avoidance of obesity. The restriction of physical exercise is not advisable. Rather asthmatics should be encouraged to participate in exercises. Short acting beta- 2 agonists should be used prior to anticipate exercise in a patient with exercise-induced asthma to alleviate symptom. Awareness of the disease is an important aspect of asthma management. It is not only the patient and their family members, but also the general practitioners at the peripheral care levels who need to continuously keep themselves updated on asthma. $^{[6]}$

This study was planned with the aim to collect information about the knowledge, attitudes, and practices of asthmatic patients regarding bronchial asthma.

\section{MATERIALS AND METHODS}

In this prospective consecutive series, patients of bronchial asthma attending out and in-patient services of Department of Pulmonary Medicine, King George's Medical University, Uttar Pradesh, Lucknow, India, a teaching and tertiary care referral hospital, during $1^{\text {st }}$ September 2008 to $31^{\text {st }}$ August 2009 were included in the present study. Cases below the age of 10 years, patients having other significant bronchopulmonary diseases associated with asthma, for example, tuberculosis, chronic obstructive pulmonary disease, bronchiectasis, and lung cancer, and so on and patients not willing to participate in the study were excluded from the study.

The patients were evaluated for confirmation of diagnosis of bronchial asthma with the help of history, examination, and spirometry before and after bronchodilators inhalation. A total of 164 patients with proposed diagnosis of bronchial asthma were recruited in the study. Out of these, 140 patients were proved to be the cases of bronchial asthma with or without allergic diseases taking the help of history, examination and spirometry. In the rest 24 patients alternate diagnosis was made, which included chronic obstructive pulmonary disease, allergic rhinitis, interstitial lung disease, bronchiectasis, pulmonary tuberculosis, lung cancer, and tonsillitis. The personal details as well as information provided by them about the different aspects of asthma provided by them like its etiology, management, and prognosis, and so on were recorded on a specially prepared questionnaire in the remaining 140 patients after obtaining an informed consent from all the participants. The questions were designed to elicit a short answer or response to a multiple choice format. The questions dealt with the nature of illness, natural history, etiology, treatment, and prognosis. The patients were asked to identify and describe possible causes of asthma with no limit being placed on the number of responses. No attempt was made to correct a wrong answer or response until the completion of the interview.

\section{RESULTS}

\section{Demographic characteristics}

The mean age of patients in our study group was 26.85 years with slight male preponderance (M:F 1.54). The mean duration of illness was 9.75 years. Mean age of onset of disease of asthma was 18.21 years. The ratio of urban to rural population was 1.19:1.

\section{Knowledge about etiology and the disease}

Out of 140 patients, more than two-third of the patients knew that they have asthma $(77 \%)$ and all of them had come to know of the diagnosis through a physician only. Only $18 \%$ patients were not aware about their diagnosis of bronchial asthma.

Results of our study show that patients of asthma identify their disease as breathlessness (around 86\%) and recurrent attacks of cough with or without expectoration (65\%). $14.4 \%$ patients attribute it to wheezing while $21.3 \%$ patients claim it to be recurrent cold and cough. $11.2 \%$ patients believe it to be some kind of allergy or associated with some allergic cause. Regarding the belief associated with asthma, 64\% patients were ignorant regarding etiology of their disease; $16.3 \%$ patients believed it to be of allergic etiology; $8.7 \%$ patients attribute it to genetic; $3.6 \%$ patients had the misconception that it is the curse of God. Small number of patients, $0.7 \%$ associate asthma with tuberculosis. Regarding the fate of asthma disease per se, majority of patients (47.1\%) were under the wrong belief that asthma is fatal in outcome. On the contrary, $31.4 \%$ patients believed that their disease is absolutely curable. Only $17.9 \%$ patients believed that their disease is preventable.

Regarding precipitating factors, 36 (25.71\%) patients could not relate to any cause or factors triggering their disease. Out of remaining 104 patients who were aware of their triggers, 98 (94.23\%) patients used to avoid them.

Regarding their idea of fate of disease, majority of patients (47.1\%) were under the wrong belief that asthma is fatal. On the contrary, $31.4 \%$ patients believed that their disease is absolutely curable. Only $17.9 \%$ patients believed that their disease is preventable.

\section{Knowledge about management}

On an average, each patient had already visited 3.2 doctors prior to coming to our institution. Oral medications in the form of tablets, capsule, and syrups remained the preferred mode of drug administration in $59.28 \%$ patients. This was followed by inhalational route in $36.42 \%$ patients. Among inhaled therapy, 58.8\% patients preferred dry powder inhalers and $41.2 \%$ patients preferred metered dose inhalers. Out of 140 patients, $73.6 \%$ were using inhalers at the time of study. Out of them, $71.8 \%$ patients were using inhalers incorrectly. Most common step of fault while using inhalers were not fully exhaling before start of inspiration $(25.43 \%)$, not shaking device (exclusively for metered dose inhalers $(16.76 \%$ ), not able to 
hold breath after full inhalation (15.03\%) and not pressing the button just after inspiration starts $(14.45 \%)$.

More than $72 \%$ patients had discontinued inhalers during the course of their treatment. The most common reasons associated with discontinuing of inhalers were cost of medications (14.4\%), forgetfulness or lack of complacency $(13.13 \%)$, dislike of medications $(8.5 \%)$, misunderstanding/lack of instruction $(8.5 \%)$, and cultural issues $(8.5 \%)$ [Table 1].

\section{Alternative modes of treatment}

Alternative system of medicine was used by $62.14 \%$ patients in the hope of getting rid of their disease. Among alternative system of medicine, homeopathic medicine was preferred most commonly (47.77\%), followed by ayurvedic medicine (39.77\%), and therapy given by saint $(12.5 \%)$ [Table 2]

\section{DISCUSSION}

There is a global problem with asthma management, either under treatment due to ignorance or distorted information/knowledge of patients about their disease (Gibson and Wilson). ${ }^{[7]}$ By 2025, an additional 100 million people will suffer from asthma due, in part, to growing urbanization and pollution. ${ }^{[8]}$ It is estimated that

\begin{tabular}{lcc}
$\begin{array}{l}\text { Table 1: Reasons for discontinuing inhaled } \\
\text { therapy ( } \boldsymbol{n}=140)\end{array}$ & Number & Percentage \\
\hline Reasons & 34 & 33.01 \\
\hline Cost of medications & 31 & 30.01 \\
Forgetfulness/complacency & 20 & 19.42 \\
Dislike of medications & 20 & 19.42 \\
Misunderstanding/lack of instruction & 20 & 19.42 \\
Cultural issues & 17 & 16.50 \\
Attitude towards ill health & 16 & 15.53 \\
Awkward regimens & 15 & 14.56 \\
Poor supervision, training or follow-up & 15 & 14.56 \\
Distant pharmacies & 12 & 11.65 \\
Difficult to carry & 11 & 10.68 \\
Anger about condition or its follow up & 7 & 6.70 \\
Stigmatization & 7 & 6.70 \\
Difficulty with inhaler devices & 7 & 6.70 \\
Side effects & 5 & 4.85 \\
Lack of response & 1 & 0.01 \\
Others (unavailability of prescribed med) & 1 & \\
\hline
\end{tabular}

\begin{tabular}{lcc}
$\begin{array}{l}\text { Table 2: Number of patients who have tried } \\
\text { alternative system of treatment }(\boldsymbol{n}=\mathbf{8 8}) \\
\text { (multiple answers) }\end{array}$ \\
\hline Alternative system of treatment & Number & Percentage \\
\hline Homeopathic & 42 & 47.8 \\
Ayurvedic & 35 & 39.8 \\
Saintly therapy & 11 & 12.5 \\
Herbal & 7 & 7.9 \\
Fish treatment & 7 & 7.9 \\
Acupuncture & 2 & 2.3 \\
Naturopathy & 1 & 1.1 \\
\hline
\end{tabular}

asthma accounts for about one in every 250 deaths worldwide. ${ }^{\left[{ }^{[8]}\right.}$ The present study reveals that an average asthmatic patient is generally ignorant about his ailment and has misconceptions, which needs to be rectified.

Most of our patients, that is, $76(54.3 \%)$ were from urban population, but still were ignorant about their disease. Studies have shown that asthma is more prevalent in urban areas than in less polluted areas. ${ }^{[0]}$

Not only large numbers of patients $(64 \%)$ were unaware about the cause of disease, but also have various wrong beliefs associated with asthma. This is a further hindrance in getting the correct knowledge, besides ignorance and illiteracy. Studies by Bedi, ${ }^{[10]}$ Pacheco et al. ${ }^{[11]}$ and Shivbalan et al., ${ }^{[12]}$ have reported similar findings. Only the physicians had disseminated the knowledge of asthma to patients who knew and accepted that they had asthma. This reinforces the need for the role that can be played by media, nongovernmental organizations and health workers in heath education regarding asthma. Formulation of national programs, conducting continuing medical education programs and frequent reminders, such as newsletters, are initial steps in improving asthma knowledge and awareness in the community. ${ }^{[13]}$

Some patients allow compromises in their life because they do not regard asthma as a chronic disease and do not understand the consequences of not following treatment regimens. ${ }^{[14]}$ Anxieties about their disease or treatments leave some asthmatics in an unending cycle of poor disease management, fear, symptoms, and resorting to alternative system of medicine in the hope of getting "cured" of asthma. We also had $62.14 \%$ patients who tried alternative system of medicine in the hope of getting their disease cured. Studies of Kishan and Singh ${ }^{[15]}$ and Pradel et al., ${ }^{[16]}$ also reported that complete trust and positive attitude of the patients is present toward other therapies for asthma. Even though inhaler therapy has been accepted as first-line therapy in developed countries, the level of acceptance is poor in our country. More than $72 \%$ patients had discontinued inhalers during the course of their treatment. Gupta and Gupta ${ }^{[17]}$ found in their study that inhalers are considered to be inferior to oral drugs by majority of patients $(76.3 \%)$. Rota halers were used less frequently $(12.1 \%)$ as compared to metered dose inhalers $(35.1 \%)$. The study by Bedi ${ }^{[10]}$ observed that majority of patients refused inhaler therapy because they are difficult to use $(50.4 \%)$, difficult to carry $(48.6 \%)$, habit forming $(41.9 \%)$, last resort $(38.2 \%)$, and social stigma $(36.6 \%)$.

A study on the same subject was also done by the authors about 10 years back. ${ }^{[9]}$ On comparing two studies, it was found that there was some improvement in the level of awareness in the patients. As compared to $79.3 \%$ of patients who were ignorant about the etiology of the disease, there are only $64 \%$ now. Whereas $42.9 \%$ were reluctant to accept the diagnosis of asthma previously, the present figure is $30 \%$. Idea regarding prognosis of the patient have also changed; previously $74.1 \%$ patients thought that their disease is fatal which has dropped down to $47.1 \%$. Patients have also become more concerned of their health. Previously, on an average, patients 
had gone to 2.1 doctors and it has increased to 3.2 in the present study. Preference to use inhaled drugs has also increased from 5.2 to $36.42 \%$ patients. These figures clearly reflect that we, as physicians, have been partly successful in creating awareness among general public about this disease. However, lot more needs to be done to achieve our goal. There are some negative results as well. In previous study, where $27.5 \%$ patients discontinued or feared using inhalers, number has increased to $72 \%$. Similarly, where $46.67 \%$ patients resorted to use alternative system of medicine, it is seen in $62.14 \%$ patients now.

Education is an essential part of treatment for all asthma patients. Education should not, however, be limited to providing knowledge, but ideally should be aimed at altering behavior. Physicians and patients need to work together to develop an asthma care program that aims for a life free from asthma symptoms and compromise.In conclusion, sincere and sustained efforts are required to disseminate knowledge about all aspects of asthma and its management among patient and to dispel their myths and misconception associated with diseases and its therapy. This will help patients to participate in self-management plans and better control of their asthma.

\section{REFERENCES}

1. Global strategy for asthma management and prevention 2012 (Update). GINASTHMA Guideline 2012 (Update). Available from: http://www. ginasthma.org [Last accessed on 2013 Jan 20].

2. Peat JK, van den Berg RH, Green WF, Mellis CM, Leeder SR, Woolcock AJ. Changing prevalence of asthma in Australian children. BMJ 1994;308:1591-6.

3. Grant EN, Turner-Roan K, Daugherty SR, Li T, Eckenfels E, Baier C, et al. Development of a survey of asthma knowledge, attitudes and perceptions: The Chicago Community Asthma Survey. Chicago Asthma Survillance Inititative Project Team. Chest 1999;116:178-83S.

4. Van Sickle D, Wright AL. Navajo perceptions of asthma and asthma medications: Clinical implications. Pediatrics 2001;108:E11.
5. Gibson PG, Powell H, Coughlan J, Wilson AJ, Abramson M, Haywood P, et al. Self-management education and regular practitioner review for adults with asthma. Cochrane Database Syst Rev 2003:CD001117.

6. Bedi RS, Singh HJ. Socio-economic factors affecting inhaler therapy compliance in asthma. Lung India 1994;12:25-6.

7. Gibson PG, Wilson AJ. The use of continuous quality improvement methods to implement practise guidelines in asthma. J Qual Clin Pract 1996;16 87-102.

8. Masoli M, Fabian D, Holt S, Beasley R. Global Initiative for Asthma (GINA) Program. The global burden of asthma: Executive summary of the GINA Dissemination Committee Report. Allergy 2004;59:469-78.

9. Prasad R, Gupta R, Verma SK. A study on perception of patients about bronchial asthma. Indian J Allergy Asthma Immunol 2003;17:85-7.

10. Bedi RS. Knowledge about asthma and its management in asthmatics of rural Punjab. Indian J Tub 1993;40:153-5.

11. Pacheco $Y$, Zureik M, Dussopt $C$, Thiriet C. Patient knowledge of asthma: Results of a national survey in Pneumology. Rev Pneumol Clin 1999;55:353-63.

12. Shivbalan $\mathrm{S}$, Balasubramanian $\mathrm{S}$, Anandnathan $\mathrm{K}$. What do parents of asthmatic children know about asthma? An indian perspective. Indian J Chest Dis Allied Sci 2005;47:81-7.

13. Al-Haddad N, Al-Ansari SS, Al-Shari AT. Impact of asthma education programme on asthma knowledge of general practitioners. Ann Saudi Med 1997;17:550-2.

14. Creer TL. Self-management of chronic illness. In: Boekaerts $M$, Pintrich PR, Zeidner M, editors. Handbook of Self-regulation. Orlando: Academic Press; 1999. p. 601-29.

15. Kishan J, Singh A. Knowledge, attitude and practice (KAP) of patients and physician of Bronchial Asthma. Proceedings of XVIII National Congress on Respiratory Diseases, Jalandhar; 1998 Nov 6-7.

16. Pradel FG, Hartzema AG, Bush PJ. Asthma self-management: The perspective of children. Patient Educ Couns 2001;45:199-209.

17. Gupta PP, Gupta KB. Awareness about the disease in asthma patients receiving treatment from physicians at different levels. Indian J Chest Dis Allied Sci 2001;43:91-5.

How to cite this article: Sodhi R, Prasad R, Kushwaha R, Kant S, Verma SK, Garg R, et al. A study to know the knowledge, attitude, and practices of patients of bronchial asthma. Int $\mathrm{J}$ Med Public Health 2013;3:159-62.

Source of Support: Nil, Conflict of Interest: None declared. 